\title{
Disponibilidade de matéria seca, composição química e consumo de forragem em pastagem de capim-elefante nas estações do ano
}

[Dry matter availability, nutritive value, and forage intake in elephantgrass pasture in different seasons of the year]

\author{
D.S.C. Paciullo ${ }^{1}$, F. Deresz ${ }^{1}$, F.C.F. Lopes $^{2}$, L.J.M. Aroeira ${ }^{1}$, M.J.F. Morenz ${ }^{2}$, R.S. Verneque ${ }^{1}$ \\ ${ }^{1}$ Embrapa Gado de Leite \\ Rua Eugênio do Nascimento, 610 \\ 36038-330 - Juiz de Fora, MG \\ ${ }^{2}$ Instituto de Zootecnia - UFRRJ - Rio de Janeiro, RJ
}

\begin{abstract}
RESUMO
Em pastagem de capim-elefante cv. Napier (Pennisetum purpureum Schum.) foram avaliadas, no período de fevereiro/1999 a novembro/2001, a disponibilidade de matéria seca (MS) acima da altura de resíduo póspastejo, a composição química, a digestibilidade in vitro da MS (DIVMS) e o consumo de forragem por vacas Holandês x Zebu lactantes, durante as estações do ano. Adotou-se o regime de lotação rotacionada, com três dias de ocupação e 30 de descanso dos piquetes. Estimativas da disponibilidade de forragem e da composição química foram realizadas mensalmente, enquanto o consumo, em dez ocasiões do período experimental. Durante a seca, as vacas receberam silagem de milho no período entre as ordenhas. A maior disponibilidade de MS de capim-elefante foi estimada em dezembro (3.402kg/ha). Entre maio e setembro, estimaram-se valores de 558 e $1.122 \mathrm{~kg} / \mathrm{ha}$, evidenciando a acentuada estacionalidade na produção de forragem. Os teores de proteína bruta (PB) e a DIVMS do pasto não diferiram entre as estações do verão, outono e primavera, mas foram menores no inverno. Os teores de fibra em detergente neutro foram menores no verão, outono e primavera, quando comparados ao valor obtido no inverno. O consumo de capim-elefante foi maior no verão, outono e primavera e menor no inverno, em decorrência da baixa quantidade de forragem na pastagem. Entretanto, o consumo de MS total não diferiu entre as estações do ano, devido à suplementação com silagem de milho.
\end{abstract}

Palavras-chave: capim-elefante, composição química, digestibilidade, ingestão, matéria seca, pastejo simulado

\begin{abstract}
The study was carried out on elephantgrass (Pennisetum purpureum Schum.) pasture, from February 1999 to November 2001, in order to evaluate the dry matter (DM) availability, observing the height of the stubble; chemical composition; in vitro dry matter digestibility (IVDMD), and dry matter intake (DMI), using Holstein $x$ Zebu lactating cows, during different seasons of the year. The paddocks were managed in a rotational grazing system, with 30 days of resting period and three days of occupation. Nutritive value and DM availability were monthly evaluated and the DMI was measured ten times during the experimental period. During dry season, cows were supplemented with corn silage during the milking intervals. The highest DM availability was estimated in December $(3,402 \mathrm{~kg} / \mathrm{ha})$. From May to September, values ranged from 558 to 1,122kg/ha, showing the strong seasonality on DM production. Means of crude protein and IVDMD did not differ among summer, autumn, and spring, but were lower during the winter. Means of neutral detergent fiber were lower in summer, autumn, and spring and higher during the winter. The pasture DMI were higher in summer, autumn, and spring and lower in the winter, due to low availability of elephantgrass. However, total DMI did not differ among seasons due to the corn silage supplementation during the winter season.
\end{abstract}

Keywords: elephantgrass, chemical composition, digestibility, intake, dry matter, hand-plucked samples

Recebido em 31 de julho de 2007

Aceito em 25 de maio de 2008

E-mail: domingos@cnpgl.embrapa.br

Apoio: FAPEMIG 


\section{INTRODUÇÃO}

Entre as gramíneas utilizadas em pastagens para alimentação de bovinos leiteiros, destaca-se o capim-elefante (Pennisetum purpureum Schum.), pelo alto potencial forrageiro e facilidade de adaptação às condições climáticas predominantes em quase todo o país, o que faz ser essa uma gramínea estudada por diversos pesquisadores (Deresz, 2001; Lopes et al., 2004ab; Carvalho et al., 2006; Silva et al., 2007). Estudos sobre sistemas de produção de leite com vacas mestiças mantidas em pastagens de capim-elefante vêm sendo desenvolvidos nos últimos anos no Brasil. Têm-se observado que produções de leite de $15.000 \mathrm{~kg} / \mathrm{ha} / 180$ dias e entre 10 e $14 \mathrm{~kg} / \mathrm{vaca} / \mathrm{dia}$ são possíveis durante a estação chuvosa, sem fornecimento de suplementação com concentrado (Aroeira et al., 1999; Deresz, 2001; Deresz et al., 2003; Carvalho et al., 2006).

Embora tais resultados demonstrem o grande potencial dessa espécie como alimento principal de vacas em lactação mantidas em regime de pastejo, tem-se observado que pastagens de capim-elefante apresentam alta capacidade de suporte somente durante a estação chuvosa, uma vez que a produção de forragem é drasticamente reduzida durante o período da seca (Aroeira et al., 1999; Paciullo et al., 2003).

Um dos principais problemas de pastagens de gramíneas tropicais é a acentuada estacionalidade na produção de forragem, resultante da existência de duas estações climáticas bem definidas (chuvas e seca). Na época das chuvas, as condições climáticas são, geralmente, favoráveis ao crescimento das espécies forrageiras, enquanto durante a seca, as condições climáticas adversas, tais como as reduções da precipitação, da temperatura e da radiação, limitam o crescimento e $o$ desenvolvimento de plantas forrageiras. Além dos efeitos do clima na produção de forragem, foram observadas mudanças no valor nutritivo do capimelefante, em função da estação do ano. Aroeira et al. (1999) observaram redução nos teores de proteína bruta e aumento da concentração de fibra em detergente neutro durante o período de inverno/primavera em relação ao de verão/outono. Em pastagens de capim-elefante, foram verificados valores de ingestão de matéria seca por vacas em lactação da ordem de 2,2 a 3,3\% do peso vivo (PV) durante o verão, e entre 0,8 e $1,5 \%$ PV durante o inverno (Aroeira et al., 1999; Lopes et al., 2004ab; Carvalho et al., 2006).
O baixo rendimento forrageiro e o comprometimento do valor nutricional no período da seca são importantes causas do pobre desempenho do rebanho manejado sob condições de pastejo. Os efeitos negativos da estacionalidade na produção de forragem e na produção animal são freqüentemente diminuídos com o uso de concentrados e suplementação volumosa à base de cana-de-açúcar mais uréia ou de silagem de milho durante o período da seca (Deresz, 2001; Lopes et al., 2004a). Entretanto, o fornecimento de alimentos volumosos como suplemento encarecem o custo de produção. Ademais, estudos conduzidos por Lucci (1976) mostraram que os altos preços dos alimentos concentrados contribuem, muitas vezes, com mais de $40 \%$ no custo de produção de leite.

O objetivo deste trabalho foi avaliar, ao longo das estações do ano, em três anos consecutivos, a disponibilidade de forragem, as características bromatológicas e o consumo de matéria seca por vacas lactantes, mantidas exclusivamente em pastagem de capim-elefante na época chuvosa, mas suplementadas com silagem de milho no inverno.

\section{MATERIAL E MÉTODOS}

O experimento foi realizado no campo experimental da Embrapa Gado de Leite, localizado no município de Coronel Pacheco/MG, entre fevereiro de 1999 e novembro de 2001, em área de pastagem de capimelefante cv. Napier. O solo da área experimental é do tipo latossolo vermelho-amarelo, distrófico de textura argilosa e relevo variando de encosta à baixada. O clima da região de acordo com a classificação de Köppen é do tipo Cwa (mesotérmico), chuvoso no verão e com inverno seco entre junho e setembro. Os dados climáticos relativos ao período experimental foram coletados na estação meteorológica do campo experimental de Coronel Pacheco - MG, distante cerca de $1.000 \mathrm{~m}$ da área experimental (Tab. 1).

A pastagem foi adubada anualmente durante a estação chuvosa com $200 \mathrm{~kg} / \mathrm{ha}$ de $\mathrm{N}$ e de $\mathrm{K}_{2} \mathrm{O}$ e $50 \mathrm{~kg} /$ ha de $\mathrm{P}_{2} \mathrm{O}_{5}$ (1.000kg da fórmula 20-05-20), fracionados em três aplicações iguais (novembro, janeiro e março).

Este trabalho foi parte integrante de um estudo em pastagem de capim-elefante, no qual foram avaliados os efeitos de estratégias de fornecimento de concentrado na produção de leite. No presente trabalho, foram consideradas as variações da disponibilidade de matéria seca, valor nutritivo da forragem e consumo de matéria seca, em função 
das estações do ano e dos anos de avaliação do experimento.

Foram utilizadas 32 vacas Holandês x Zebu no primeiro ano experimental (1998/1999) e 24 nos dois anos subseqüentes (1999/2000 e 2000/2001), dispostas em bloco segundo a produção de leite, data do parto e peso vivo, o qual foi, em média, de $480 \mathrm{~kg}$, para o período experimental. Para avaliação do consumo de matéria seca (MS), foram considerados apenas os animais que ao longo do período experimental não receberam suplementação com concentrado (16 vacas em 1998/1999 e 12 vacas em 1999/2000 e 2000/2001). Foi usado o delineamento experimental de blocos casualizados, com quatro repetições. No primeiro ano, foram usadas quatro vacas por bloco, quantidade que foi reduzida para três nos anos subseqüentes. A área de capim-elefante (6ha) foi manejada em pastejo rotativo ( 5 vacas/ha), com três dias de ocupação e 30 de descanso/piquete.

Tabela 1. Médias das temperaturas máxima (TMAX) e mínima (TMIN) e precipitação pluviométrica total, por estação do ano, observadas durante os anos de 1999, 2000 e 2001

\begin{tabular}{lccccccccc}
\hline & \multicolumn{3}{c}{ TMAX $\left({ }^{\circ} \mathrm{C}\right)$} & \multicolumn{3}{c}{ TMIN $\left({ }^{\circ} \mathrm{C}\right)$} & \multicolumn{3}{c}{ Precipitação $(\mathrm{mm})$} \\
\cline { 2 - 10 } Estação & \multicolumn{3}{c}{ Ano } & \multicolumn{3}{c}{ Ano } & \multicolumn{3}{c}{ Ano } \\
& 1999 & 2000 & 2001 & 1999 & 2000 & 2001 & 1999 & 2000 & 2001 \\
\hline Verão & 31,1 & 29,7 & 31,7 & 20,0 & 19,5 & 19,3 & 678,3 & 717,8 & 457,1 \\
Outono & 26,6 & 27,4 & 28,5 & 14,4 & 13,8 & 15,4 & 57,3 & 57,1 & 108,2 \\
Inverno & 26,4 & 25,8 & 26,9 & 11,8 & 11,9 & 11,8 & 15,7 & 95,2 & 19,0 \\
Primavera & 27,3 & 31,1 & 28,6 & 16,4 & 18,2 & 18,0 & 453,3 & 441,0 & 558,1 \\
\hline
\end{tabular}

Fonte: Estação metereológica do campo experimental de Coronel Pacheco.

Durante a época seca do ano, os animais foram confinados e receberam silagem de milho à vontade no intervalo entre a ordenha da manhã e a da tarde. Além disso, para elevar o teor de proteína bruta da dieta todas as vacas receberam, individualmente, $1 \mathrm{~kg}$ de farelo de soja, metade na ordenha da manhã e o resto na da tarde. Após a ordenha da tarde, os animais eram levados para os piquetes de capimelefante. Nos currais, as vacas tinham acesso à água e à mistura mineral. $\mathrm{O}$ consumo de silagem foi medido, individualmente, durante três dias consecutivos, uma vez por semana, em cochos do tipo Calan-Gates ${ }^{1}$.

A disponibilidade de MS existente acima da altura de resíduo pós-pastejo foi estimada mensalmente durante o período experimental, adotando-se metodologia preconizada por Paciullo et al. (2003), brevemente descrita a seguir: três touceiras de cada piquete escolhidas visualmente, foram colhidas, simulando o pastejo, das quais a primeira representou as de porte baixo, a segunda, as de porte médio e a terceira, as de porte alto. Toda parte aérea (folhas e colmos tenros) foi amostrada, pesada e levada à estufa para determinação da MS. $\mathrm{O}$ peso seco médio das três touceiras multiplicado pelo número de touceiras contadas em área de $49 \mathrm{~m}^{2}$ foi usado para a estimativa da disponibilidade de forragem/ha/animal.

\footnotetext{
${ }^{1}$ American Calan Inc., Northewood, NH, EUA.
}

Nas amostras secas e moídas foram determinados os teores de proteína bruta (PB) segundo AOAC (Official..., 1990), fibra em detergente neutro (FDN) e fibra em detergente ácido (FDA) de acordo com metodologia de Van Soest et al. (1991) e a digestibilidade in vitro da matéria seca (DIVMS), de acordo com Tilley e Terry (1963).

O consumo de MS de pasto foi estimado em 10 ocasiões do período experimental: fevereiro, abril, junho e agosto de 1999; janeiro, março/abril e junho de 2000 e fevereiro/março, maio e julho de 2001. A produção fecal das vacas foi estimada utilizando $10 \mathrm{~g}$ /vaca/dia de óxido crômico $\left(\mathrm{Cr}_{2} \mathrm{O}_{3}\right)$ como indicador externo, envolvido em cápsulas de papel e administrado por via oral durante 12 dias consecutivos. Os sete primeiros dias foram considerados como período de estabilização do fluxo de excreção do indicador. O óxido crômico foi administrado aos animais em duas doses diárias de $5 \mathrm{~g}$ cada, imediatamente após as ordenhas da manhã (7h) e da tarde (14h). As fezes foram coletadas duas vezes ao dia, diretamente do reto dos animais, durante cinco dias, contados após o sétimo dia de administração. As amostras foram secas em estufa de ventilação forçada regulada a $55^{\circ} \mathrm{C}$, moídas em moinho de facas tipo Willey com peneira de malha $1 \mathrm{~mm}$ e submetidas à digestão nitroperclórica, segundo Kimura e Miller (1952). Após a digestão, a concentração de cromo $(\mathrm{Cr})$ foi determinada por espectrofotometria de absorção atômica. A produção fecal (PF) foi calculada usando a fórmula: $\mathrm{PF}=$ cromo administrado 
diariamente (g/dia)/concentração de cromo na MS fecal $(\mathrm{g} / \mathrm{kg})$. O consumo diário de MS (CMS) foi estimado com o uso da fórmula, conforme indicado por Astigarraga (1997); CMS (g/dia) $=\mathrm{PF} \times$ $100 /(100$ - DIVMS). No tratamento em que a dieta foi exclusivamente de capim-elefante, a fórmula acima foi aplicada diretamente. Quando os animais receberam farelo de soja ou silagem de milho, foi determinada a DIVMS de cada alimento e a estimativa de suas contribuições para a produção fecal foi calculada. O consumo de capim-elefante foi obtido indiretamente por diferença.

O experimento foi analisado em parcelas subdivididas, em que nas parcelas foram alocados os anos de condução do experimento e nas subparcelas, as estações do ano. Os dados foram submetidos à análise de variância segundo o modelo estatístico:

$\mathrm{Y}_{\mathrm{ijk}}=\mu+\mathrm{B}_{\mathrm{i}}+\mathrm{A}_{\mathrm{j}}+\varepsilon(\mathrm{a})+\mathrm{E}_{\mathrm{k}}+\mathrm{AE}_{\mathrm{jk}}+\varepsilon(\mathrm{b})$, em que, $Y_{i j k}=$ observação relativa à $\mathrm{k}^{\mathrm{a}}$ estação do $\mathrm{j}^{\mathrm{o}}$ ano; $\mu=$ média geral; $B_{i}=$ efeito do $i^{\circ}$ bloco; $A_{j}=$ efeito do $\mathrm{j}^{\mathrm{o}}$ ano; $\varepsilon(\mathrm{a})=$ erro aleatório associado à parcela; $\mathrm{E}_{\mathrm{k}}=$ efeito da $\mathrm{k}^{\mathrm{a}}$ estação do ano; $\mathrm{AE}_{\mathrm{jk}}=$ interação do $\mathrm{j}^{\mathrm{o}}$ ano com a $\mathrm{k}^{\mathrm{a}}$ estação do ano; $\varepsilon(\mathrm{b})=$ erro aleatório associado à subparcela.

As análises de variância foram realizadas com dados não transformados, utilizando-se o procedimento GLM do SAS (User's..., 1985). Para os valores de disponibilidade de forragem, foi realizada análise de regressão de acordo com os meses de avaliação (1 a 12 representando os meses de janeiro a dezembro, respectivamente). A escolha do modelo mais adequado baseou-se na significância do efeito da regressão e nãosignificância dos desvios da regressão avaliados pelo teste $\mathrm{F}$.

\section{RESULTADOS E DISCUSSÃO}

A disponibilidade de forragem variou $(\mathrm{P}<0,01)$ quadraticamente com os meses de avaliação, independentemente do ano, motivo pelo qual se ajustou uma única equação de regressão para os três anos (Fig. 1). Pela equação de regressão em que $X$ representa os meses de avaliação e Y a disponibilidade de forragem $(\mathrm{kg} / \mathrm{ha})$, foi possível estimar valor mínimo de $558 \mathrm{~kg} / \mathrm{ha}$ de MS entre os meses de junho e julho. A maior disponibilidade de MS, estimada em dezembro, foi de $3.402 \mathrm{~kg} / \mathrm{ha}$ de MS. Entre maio e setembro, estimaram-se valores entre 558 e $1.122 \mathrm{~kg} / \mathrm{ha}$ de $\mathrm{MS}$, os quais evidenciaram a acentuada estacionalidade na produção de forragem do capim-elefante nas condições da Zona da Mata de Minas Gerais. A equação matemática apresentada pode ser ferramenta útil para obtenção de estimativas da disponibilidade de forragem ao longo do ano, a fim de se adequar planos nutricionais para vacas lactantes em pastagem de capim-elefante.

A estacionalidade é resultado das baixas taxas de acúmulo diário de MS, influenciadas negativamente pelas baixas temperaturas e pela disponibilidade hídrica. A queda das taxas de acúmulo, durante os meses do inverno, está relacionada, principalmente, ao comportamento das variáveis morfogênicas da gramínea, as quais, segundo Paciullo et al. (2003), diminuíram de 0,21 para 0,09 folha/perfilho.dia (taxa de aparecimento de folhas) e de 17,6 para $2,4 \mathrm{~cm} /$ perfilho.dia (taxa de alongamento de folhas) quando se avaliou uma pastagem de capim-elefante no verão e inverno, respectivamente. Associadas a essas variações, os autores encontram taxas de acúmulo de MS de $125,6 \mathrm{~kg} / \mathrm{ha} /$ dia durante o verão e de $8,9 \mathrm{~kg} / \mathrm{ha} /$ dia no inverno.

Os valores de disponibilidade de MS obtidos neste trabalho são semelhantes aos relatados na literatura em trabalhos que estimaram a disponibilidade de biomassa de capim-elefante por meio do pastejo simulado (Aroeira et al., 1999; Deresz, 2001). Sob o ponto de vista de nutrição animal, a técnica usada apresenta a vantagem de estimar valores próximos da biomassa potencialmente consumível por animais em pastejo, considerando a preferência dos ruminantes em consumirem folhas (Chacon et al., 1978).

Os teores de PB foram influenciados $(\mathrm{P}<0,05)$ pela interação estação do ano $\mathrm{x}$ ano de avaliação. Os teores de $\mathrm{PB}$ foram maiores no verão, outono e primavera, durante os anos de 1999 e 2000. Em 2001, os maiores teores foram observados no outono, enquanto os valores intermediários ocorreram no verão e primavera. Independentemente do ano, o capim-elefante apresentou os menores teores de PB no inverno (Tab. 2). Ressalta-se que os valores obtidos no inverno, ainda estiveram acima de $11,0 \%$, os quais estão dentro da média normalmente relatada para gramíneas tropicais. Aroeira et al. (1999) e Deresz (2001) encontraram teores de PB para o capimelefante entre 10,0 e 14,5\%, dependendo da estação do ano. Considerando os teores de PB obtidos neste trabalho, díspares entre 11,4 (inverno de 2001) e $16,6 \%$ (outono de 2000), e os resultados dos autores citados, deduz-se que o capim-elefante sob pastejo apresenta, ao longo do ano, teores de PB que não limitariam o consumo voluntário de vacas em lactação, levando-se em conta o nível crítico de 7\% (Milford e Minson, 1966), abaixo do qual poderia ocorrer redução do consumo de animais em pastagem. 


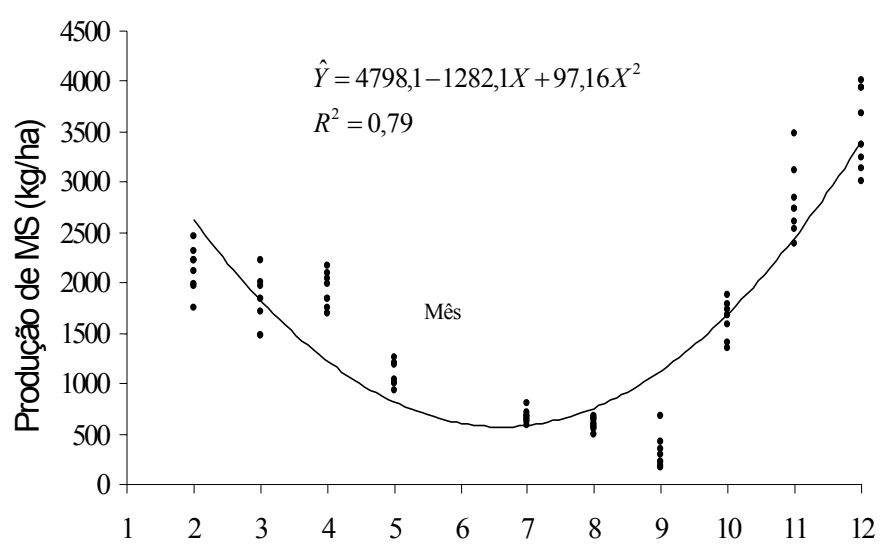

Figura 1. Regressão da disponibilidade de matéria seca (MS) em função do mês do ano (números de 1 a 12 representam os meses de janeiro a dezembro).

Tabela 2. Teores de proteína bruta (\% da matéria seca) do capim-elefante, em função do ano e da estação do ano

\begin{tabular}{lcccc}
\hline Ano & Verão & Outono & Inverno & Primavera \\
\hline 1999 & $14,2 \mathrm{Ba}$ & $15,4 \mathrm{Aa}$ & $12,2 \mathrm{Ab}$ & $15,2 \mathrm{Aa}$ \\
2000 & $16,3 \mathrm{Aa}$ & $16,6 \mathrm{Aa}$ & $12,8 \mathrm{Ab}$ & $15,1 \mathrm{ABa}$ \\
2001 & $14,8 \mathrm{Bab}$ & $15,6 \mathrm{Aa}$ & $11,4 \mathrm{Ac}$ & $13,6 \mathrm{Bb}$ \\
\hline
\end{tabular}

Médias seguidas por letras diferentes, minúsculas na linha e maiúscula na coluna, diferem $(\mathrm{P}<0,05)$ entre si.

Quanto à variação dos teores de PB em função dos anos de avaliação, verificaram-se valores semelhantes nas estações do outono e inverno, mas diferentes no verão e na primavera, provavelmente em decorrência das variações climáticas (Tab. 1).

Os teores de FDN variaram $(\mathrm{P}<0,05)$ com a interação estação do ano $\mathrm{x}$ ano de avaliação (Tab. 3). No inverno, foram verificados os maiores valores, independentemente do ano. Enquanto em 1999 e 2000 os menores valores foram semelhantes no verão, outono e primavera, em 2001, valores intermediários foram obtidos no verão e na primavera e o menor teor, no outono.

Efeito $(\mathrm{P}<0,05)$ de ano de avaliação foi observado no outono, quando maiores teores foram obtidos em
1999 e 2000 e menores em 2001. Nas demais estações do ano, os teores de FDN foram semelhantes $(\mathrm{P}>0,05)$ entre si.

Os teores de FDN, com valores extremos entre 67,5 e $73,8 \%$ (Tab. 3), se assemelham àqueles normalmente relatados para o capim-elefante sob pastejo (Aroeira et al., 1999; 2001; Deresz, 2001; Lopes et al., 2004a; Carvalho et al., 2006).

Uma análise simultânea dos resultados observados para os teores de PB e FDN demonstra a pequena variação nutricional do capim-elefante ao longo das estações do verão, outono e primavera e redução do valor nutricional durante o inverno, em decorrência dos menores teores de PB e maiores de FDN.

Tabela 3. Teores de fibra em detergente neutro (\% da matéria seca) do capim-elefante, em função do ano e da estação do ano

\begin{tabular}{lcccc}
\hline Ano & Verão & Outono & Inverno & Primavera \\
\hline 1999 & $68,0 \mathrm{Ab}$ & $69,2 \mathrm{Ab}$ & $73,4 \mathrm{Aa}$ & $67,8 \mathrm{Ab}$ \\
2000 & $68,9 \mathrm{Ab}$ & $68,4 \mathrm{Ab}$ & $73,8 \mathrm{Aa}$ & $67,5 \mathrm{Ab}$ \\
2001 & $67,5 \mathrm{Abc}$ & $67,1 \mathrm{Bc}$ & $72,7 \mathrm{Aa}$ & $69,2 \mathrm{Ab}$ \\
\hline
\end{tabular}

Médias seguidas por letras diferentes, minúsculas na linha e maiúsculas na coluna, diferem $(\mathrm{P}<0,05)$ entre si.

Verificou-se efeito $(\mathrm{P}<0,01)$ da interação estação do ano $\mathrm{x}$ ano de avaliação nos coeficientes de DIVMS (Tab. 4). Os menores valores de digestibilidade foram observados no inverno, independentemente do ano. Nas demais estações, a DIVMS variou conforme o ano de avaliação. Assim, em 1999 e 
2001, o capim-elefante apresentou valores intermediários no verão e primavera e maiores no outono, enquanto em 2000, os valores obtidos no verão, outono e primavera foram semelhantes entre si. A redução da DIVMS durante a estação de inverno, esteve relacionada à elevação dos teores de FDN e diminuição dos de PB.
$\mathrm{Na}$ literatura nacional, a DIVMS do pasto de capim-elefante em regime de lotação rotacionada variou, dependendo do manejo e da estação do ano, de 50,0 a $68,5 \%$, conforme citado em revisão realizada por Lopes et al. (2004a). Observa-se que a amplitude de variação da DIVMS deste estudo $(54,0$ a $62,1 \%)$ está dentro da faixa citada acima.

Tabela 4. Digestibilidade in vitro da MS (DIVMS, \%) do capim-elefante, em função do ano e da estação do ano

\begin{tabular}{lcccc}
\hline Ano & Verão & Outono & Inverno & Primavera \\
\hline 1999 & $56,9 \mathrm{Bb}$ & $60,0 \mathrm{Aa}$ & $54,0 \mathrm{Bc}$ & $56,6 \mathrm{Bb}$ \\
2000 & $62,1 \mathrm{Aa}$ & $61,0 \mathrm{Aa}$ & $58,0 \mathrm{Ab}$ & $62,0 \mathrm{Aa}$ \\
2001 & $58,0 \mathrm{Bb}$ & $61,8 \mathrm{Aa}$ & $54,7 \mathrm{Bc}$ & $57,9 \mathrm{Bb}$ \\
\hline
\end{tabular}

Médias seguidas por letras diferentes, minúsculas na linha e maiúscula na colunas, diferem $(\mathrm{P}<0,05)$ entre si.

O consumo de MS de pasto variou $(\mathrm{P}<0,01)$ de 0,61 a $2,7 \%$ do PV, em função da interação estação $x$ ano de avaliação (Tab. 5). Durante o verão e o outono, quando não houve suplementação com concentrado, os valores de consumo estiveram entre 2,0 e $2,7 \%$ do $\mathrm{PV}$, com pequena redução dos níveis de consumo de pasto entre o verão e o outono, especialmente nos anos de 2000 e 2001, o que está de acordo com os relatos de Lopes et al. (2004a). No inverno, o consumo de pasto foi acentuadamente menor $(\mathrm{P}<0,01)$ do que os observados nas outras duas estações. De fato, Lopes et al. (2004a) haviam verificado decréscimo significativo no consumo de capim-elefante por vacas em lactação, em regime exclusivo de pastejo, entre os meses de fevereiro e setembro. Esses autores ajustaram uma equação de regressão do consumo diário de MS de capim-elefante (\%PV) em relação ao mês de avaliação, durante o período supracitado, cujo coeficiente de regressão indicou decréscimo na ingestão de capim-elefante de $0,36 \% \mathrm{PV} / \mathrm{mês}$.

Tanto a variação estacional da composição química e da DIVMS, quanto à da disponibilidade de forragem, poderiam explicar a variação dos resultados de consumo de MS. Entretanto, considerando os valores observados, deduz-se que os teores de PB e FDN e a DIVMS comportariam apenas pequena variação nos valores de consumo de MS. Por essa razão, os principais efeitos negativos na ingestão de MS poderiam ser atribuídos às baixas disponibilidades de forragem, observadas no inverno.

O fornecimento de silagem de milho para os animais, além da suplementação com farelo de soja durante o período de inverno, permitiu relativa estabilização do nível de consumo total pelas vacas ao longo das estações do ano (Tab. 5). Assim, os valores estimados em 1999 foram semelhantes $(\mathrm{P}<0,01)$, entre as estações. Em 2000 e 2001, observaram-se consumos estatisticamente iguais, quando comparados o verão e o inverno, embora no outono tenham sido verificados valores menores que nas demais estações. Tal fato realça a necessidade de suplementação volumosa para vacas em lactação, durante o período de escassez de pasto, conforme também evidenciado por outros autores (Aroeira et al., 1999; Deresz et al., 2003).

Tabela 5. Consumo médio diário de MS (\%PV) do pasto de capim-elefante e total, em função do ano e da estação do ano

\begin{tabular}{cccc}
\hline Ano & Verão & Outono & Inverno \\
1999 & & Consumo de pasto \\
2000 & $2,45 \mathrm{Aa}$ & $2,47 \mathrm{Aa}$ & $0,80 \mathrm{Bb}$ \\
2001 & $2,70 \mathrm{Aa}$ & $2,27 \mathrm{Ab}$ & $1,11 \mathrm{Ac}$ \\
\hline & $2,54 \mathrm{Aa}$ & $2,00 \mathrm{Bb}$ & $0,61 \mathrm{Bc}$ \\
1999 & & Consumo total & \\
2000 & $2,45 \mathrm{Aa}$ & $2,47 \mathrm{Aa}$ & $2,77 \mathrm{Aa}$ \\
2001 & $2,70 \mathrm{Aa}$ & $2,27 \mathrm{Ab}$ & $2,46 \mathrm{Bab}$ \\
\hline
\end{tabular}

${ }^{a}$ Valores apresentados para o inverno referem-se ao consumo de pasto, somados aos consumos individuais médios de silagem de milho (1,80; 1,20 e 1,50\%PV, em 1999, 2000 e 2001, respectivamente) e de farelo de soja (0,16\%PV). Médias seguidas por letras diferentes, minúsculas na linha e maiúsculas na coluna, diferem $(\mathrm{P}<0,05)$ entre si. 
O consumo obtido durante a época das chuvas comportou produções médias de leite de $10 \mathrm{~kg} / \mathrm{vaca} / \mathrm{dia}$, exclusivamente em pastagem, conforme também observado por diversos autores com a mesma gramínea (Deresz, 2001; Carvalho et al., 2006). No período de inverno, a suplementação volumosa e o fornecimento de farelo de soja possibilitaram consumos totais de matéria seca entre 2,28 a 2,77\% do PV, o que refletiu em produção média de leite da ordem de $9,5 \mathrm{~kg} / \mathrm{vaca} / \mathrm{dia}$, entre os meses de junho e setembro. A produção de leite média do período experimental, considerando todas as estações do ano, foi de $9,7 \mathrm{~kg} / \mathrm{vaca} / \mathrm{dia}$, valor esse semelhante ao obtido por Carvalho et al. (2006), de 9,6kg/vaca/dia, para vacas mantidas em pastagem de capim-elefante submetidas a manejo semelhante ao do presente estudo.

\section{CONCLUSÕES}

O capim-elefante sob pastejo apresenta baixa disponibilidade de forragem e redução dos teores de proteína bruta e da digestibilidade da matéria seca durante o inverno. Durante o inverno, a redução acentuada da disponibilidade de pasto é a principal responsável pelo decréscimo do nível de consumo de matéria seca. A suplementação volumosa durante o inverno minimiza os efeitos negativos da estacionalidade da produção de forragem do capimelefante.

\section{REFERÊNCIAS BIBLIOGRÁFICAS}

AROEIRA, L.J.M.; LOPES, F.C.F.; DERESZ, F. et al Pasture availability and dry matter intake of lactating crossbred cows grazing elephant grass (Pennisetum purpureum, Schum.). Anim. Feed Sci. Tecnol., v.78, p.313324, 1999.

AROEIRA, L.J.M.; LOPES, F.C.F.; SOARES, J.P.G. et al. Daily intake of lactating crossbred cows grazing elephant grass rotationally. Pesq. Agropec. Bras., v.36, p.911-917, 2001.

ASTIGARRAGA, L. Técnicas para la medición del consumo de rumiantes en pastoreo. In: SIMPÓSIO SOBRE AVALIACC̃̃O DE PASTAGENS COM ANIMAIS, 1997. Anais... Maringá: UEM, 1997. p.1-23.

CARVALHO, C.A.B.; DERESZ, F.; ROSSIELLO, R.O.P. et al. Influência de intervalos de desfolha e de alturas do resíduo pós-pastejo sobre a produção e a composição da forragem e do leite em pastagens de capim-elefante. Bol. Ind. Anim., v.62, p.177-188, 2006
CHACON, E.; STOBBS, T.H.; DALE, M.B. Influence of sward characteristics on grazing behaviour and growth of Hereford steers grazing tropical grass pasture. Aust. J. Agric. Res., v.29, p.89-102, 1978.

DERESZ, F. Influência do período de descanso da pastagem de capim-elefante na produção de leite de vacas mestiças Holandês-Zebu. Rev. Bras. Zootec., v.30, p.461-469, 2001.

DERESZ, F.; MATOS, L.L.; MOZZER, O.L. et al. Produção de leite de vacas mestiças Holandês x Zebu em pastagem de capim-elefante, com e sem suplementação de concentrado durante a época das chuvas. Arq. Bras. Med. Vet. Zootec., v.55, p.334-340, 2003.

KIMURA, F.T.; MILLER, V. F. Chromic oxide measurement: improved determination of chromic oxide in cow feed and faeces. Agric. Food Chem., v.111, p.633-635, 1952

LOPES, F.C.F.; AROEIRA, L.J.M.; RODRIGUEZ, N.M. et al. Efeito da suplementação e do intervalo de pastejo sobre a qualidade da forragem e consumo voluntário de vacas Holandês x Zebu em lactação em pastagem de capimelefante. Arq. Bras. Med. Vet. Zootec., v.56, p.355-362, 2004a.

LOPES, F.C.F.; RODRIGUEZ, N.M.; AROEIRA, L.J.M. et al. Relação entre variáveis na regulação do consumo de vacas Holandês x Zebu em lactação sob pastejo em capim-elefante. Arq. Bras. Med. Vet. Zootec., v.56, p.52-60, $2004 \mathrm{~b}$

LUCCI, C.S. A produção de leite e os alimentos volumosos. Zootecnia, v.14, p.81-89, 1976.

MILFORD, R.; MINSON, D.J. Intake of tropical pasture species. In: CONGRESSO INTERNACIONAL DE PASTAGENS, 9. 1965, São Paulo. Anais... São Paulo: Alarico, 1966. p.815-22.

OFFICIAL methods of analysis. 15.ed. Virginia: AOAC, 1990. 1298 p.

PACIULLO, D.S.C.; DERESZ, F.; AROEIRA, L.J.M. et al. Morfogênese e acúmulo de biomassa foliar em pastagem de capim-elefante avaliada em diferentes épocas do ano. Pesq. Agropec. Bras., v.38, p.881-887, 2003

SILVA, P.A.; VALADARES FILHO, S.C.; VALADARES, R.F.D. et al. Valor energético do capim-elefante em diferentes idades de rebrota e estimativa da digestibilidade in vivo da fibra em detergente neutro. Arq. Bras. Med. Vet. Zootec., v. 59, p.711-718, 2007.

TILLEY, J.M.A.; TERRY, R.A. A two-stage technicique for the in vitro digestion of forrage digestibility. J. Br. Grassl. Soc., v.18, p.104-11, 1963.

USER's guide: statistics, version 6.03. Cary: SAS Institute, 1985. 1028p.

VAN SOEST, P.J.; ROBERTSON, J.B.; LEWIS, B.A. Methods for dietary fiber, neutral detergent fiber, and non starch polysaccharides in relation to animal nutrition. $J$. Dairy Sci., v.74, p.3583-3597, 1991 